\title{
環境モデルを用いたロボット作業の オフラインプログラミングシステムの試作*
}

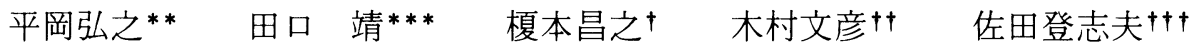

\begin{abstract}
Development of Off-line Programming System of Robot Operations Based on Environment Models
\end{abstract}

Hiroyuki Hiraoka, Yasushi Taguchi, Masayuki Enomoto,

Fumihiko KImURa and Toshio Sata

A model-based off-line programming system of the robot operations is developed for industrial use. Environment modelling system based on the solid modelling system GEOMAP-III, is developed as a tool for maintaining the information of the working environment of the robot, such as robot itself, parts to be assembled, obstacles, etc., and other necessary information for the robotic tasks. A high-level assembly description language which describes assembly process in terms of the operations on the parts to be assembled instead of motion of the robot itself, is designed. By utilizing the information of the environment model, the system generates information of the robot motion from this high-level description, simulating the changes in the environment. Feasibility checks of the generated robot motion, detection of collisions between the robot and obstacles, calculation of necessary grasping force, are performed in the process and the results are displayed to the operator for easy debugging of the program. Preparation for sensory interactive robot motion in the run-time system, is also considered. As examples, some assembly operations are programmed by the system with high-level language.

Key words : off-line robot programming system, solid modelling, world model, robot simulation, robot language

\section{1.はじめに}

\section{1 ロボットのオフラインプログラミング \\ ロボットの普及に従い, どのようにしてロボット作} 業を教示するか,ということが問題になってきている. 従来のティーチングプレイバックによる作業教示法 は，時間がかかるばかりでなく，作業のわずかな変更 に対しても対応が容易でない。ロボットのオフライン プログラミングシステムは，ロボットの運動を記述す

* 原稿受付 昭和 60 年 11 月 15 日. 昭和 58 年度精機学会秋 季大会学術講演会 (昭和 58 年 10 月 14 日), 昭和 59 年度 精機学会春季大会学術講演会 (昭和 59 年 3 月 27 日) 捄よ び昭和 60 年度精機学会秋季大会学術講演会 (昭和 60 年 10 月 14 日）にて発表

** 正会員 東京大学生産技術研究所（東京都港区六本木 7-22-1)

*** 正会員 日本アイ・ビー・エム(株)（東京都新宿区西新 宿 2-6-1, 新宿住友ビル)

†正会員 日本電気(株)（川崎市幸区塚越 3-484）

t+正会員 東京大学工学部 (東京都文京区本郷 7-3-1)

†十 正会員 東京大学工学部 (現, 理化学研究所; 和光市広 沢 2-1)
る言語入力に基づいてロボット動作のデータを生成で きるので，そうした問題点を解決する有効な手段とし て研究されている1).

ロボットのプログラミング言語は様々なものが開発 されているが，ロボット動作に直接対応した動作レベ ルの言語はプログラミングが繁雑で手間がかかるた め,より高度の言語の開発が望まれてきた。言語の高 級化に伴い，ロボットの作業を記述するプログラム部 分は簡潔なものになってきつつある2が，ロボットの 作業環境についてはその簡潔な表現法と強力な管理手 法の開発が遅れており，このことがオフラインプログ ラミングシステムの実用化の一つの障害になっている とも考えられる.

そこで, 近年開発が進んでいる CAD システム, 特に 幾何モデリングシステムを利用して，ロボットのプロ グラミングでの環境の扱いを容易にする方法が試みら れている31. 本論文では, CAD/CAM システムの構築 が容易にできるよう設計された立体形状モデリングシ ステム GEOMAP-III")を用いてモデルベースのオフ 


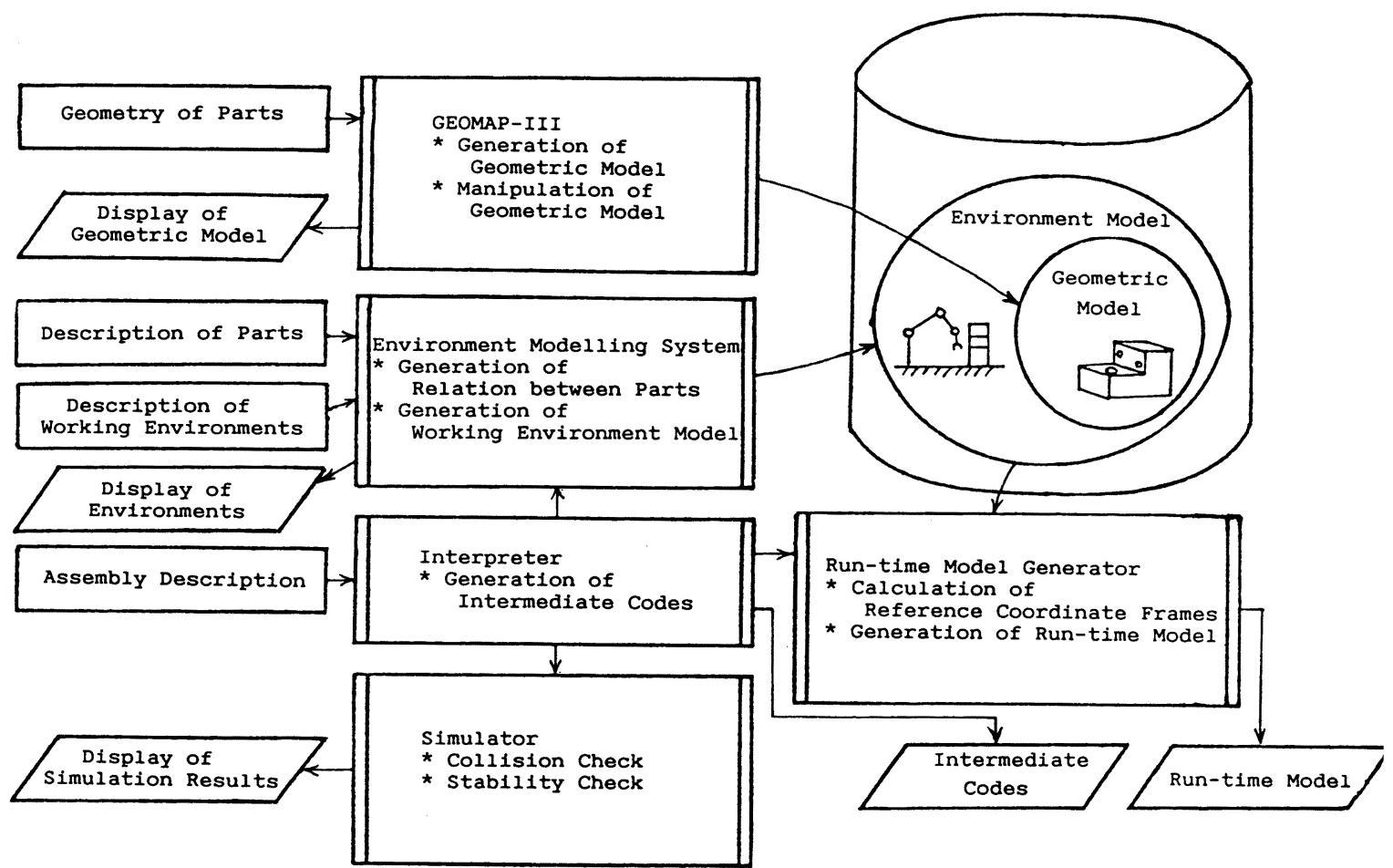

Fig. 1 Configuration of off-line robot system and its data processing

ラインプログラミングシステムを試作したので，その 機能と処理について報告する.

1.2 ロボットシステムの全体構成

本研究では, ロボットを動作させるシステムをオフ ラインのプログラミングシステムとオンラインでロ ボットを制御するランタイムシステムに分けるのが実 用的であると考えた。環境モデルを，オフラインシス テムで高度の言語処理を可能にするために利用するば かりでなく, ランタイムシステムでセンサ情報の処理 を容易にする目的でも用いることを考えている。この ために，オフラインシステムは, ロボットの動作コマ ンドと共に, ランタイムジステムで用いる簡単なモデ ル（ランタイムモデルと呼ぶ）をも生成する。

\section{2. オフラインシステムの構成}

\section{1 処理の流れと構成}

本研究のロボット作業プログラミングシステムの処 理の流れとシステム概要を図 1 に示す.オペレータは, 以下の順に処理を進める。

（1）組立対象部品, ロボット，作業環境に関する形 状モデルを形状モデリングシステムGEOMAP. IIIを用いて生成する。

（2）部品に関して, 初期状態と最終状態における位 置や部品間関係を入力する. ロボットに関しては
リンク番号やリンク間の拘束関係を指定する。

（3）作業手順を作業記述ロボット言語を用いて入 力する。ロボット言語の各コマンドごとに, 衝突 チェックや安定性チェックをシステムが行うの で，その結果をディスプレイ上で確認する。

ロボットや作業環境についての定義は, 一度行えば, 再び行ら必要はない,また，(1)，(2)の入力について は, 設計・生産の統合化 ${ }^{5)}$ が進めば，そのほとんどが不 要になると考えられる。

\section{2 環境モデルの構造}

ロボット，作業対象部品を含めた作業環境を計算機 内にモデル化したものを環境モデルと呼ぶ. 図 2 に示 すように，環境モデルは次の 4 項目の情報を有する.

a）形状情報： 3 次元空間内の物体の幾何情報お よび位相情報（面，稜線，頂点等）である。

b）位置情報： 作業が行われる前の部品群の位 置, 姿勢 (初期状態) と, すべての作業が行われ た後の部品群の位置, 姿勢（完成状態）に関する 情報である。一つの部品を複数回移動するときに は，移動するごとにシステムが初期状態の位置情 報を更新する。

c）接続情報： 2 つの部品間, リンク間に存在す る各種の対偶関係を扱う。対偶は, 平面, 軸, 穴 等の要素 (以下, 形状要素と呼ぶ) の間の関係記 


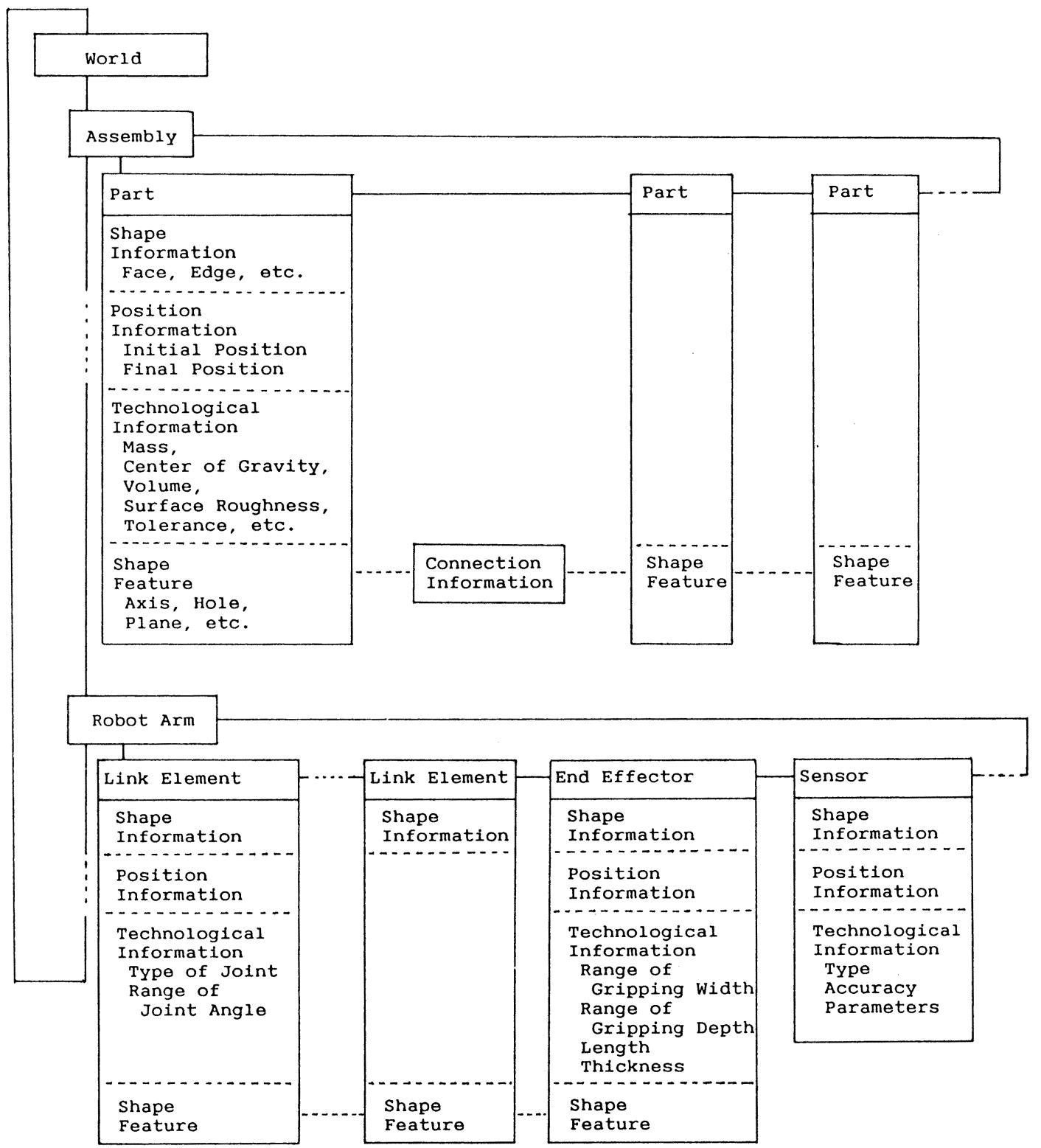

Fig. 2 Structure of environment model

述であり, 本システムでは, 平面対偶, 軸穴対偶, ねじ対偶, 固定の 4 種を定義できる. 形状要素は, 形状モデルには明白には表現されていないが，形 状情報をもとにシステムが自動的に定義する。

d）技術情報：部品, リンク及び形状要素に固有 の数値データである。部品には, 物体の重心, 重 量, 体積, 比重, 仮想包絡球の中心及び半径, 把 握に関する情報が，ハンドには，実現可能な把握 幅や把握深さに関するデータが与えられている。 センサに固有の情報としては, センサの種類とそ
れに応じた各種のパラメータが, 形状要素に固有 の情報としては, 表面の種類, 表面粗さ, ねじの 呼び径, 組付精度等がある。

\section{3 作業記述ロボット言語}

本研究における作業記述ロボット言語は, 組立作業 を主な対象としており, 対象部品への操作を指示する だけでロボットの動きを生成する，いわゆる対象物レ ベルのロボット言語である。表 1 にその仕様を示す。 組立作業命令は, 実際の自動車, 電気製品の組立作業 における作業パターンの調査から, 位置合わせ命令と 
Table 1 Keywords of assembly description language

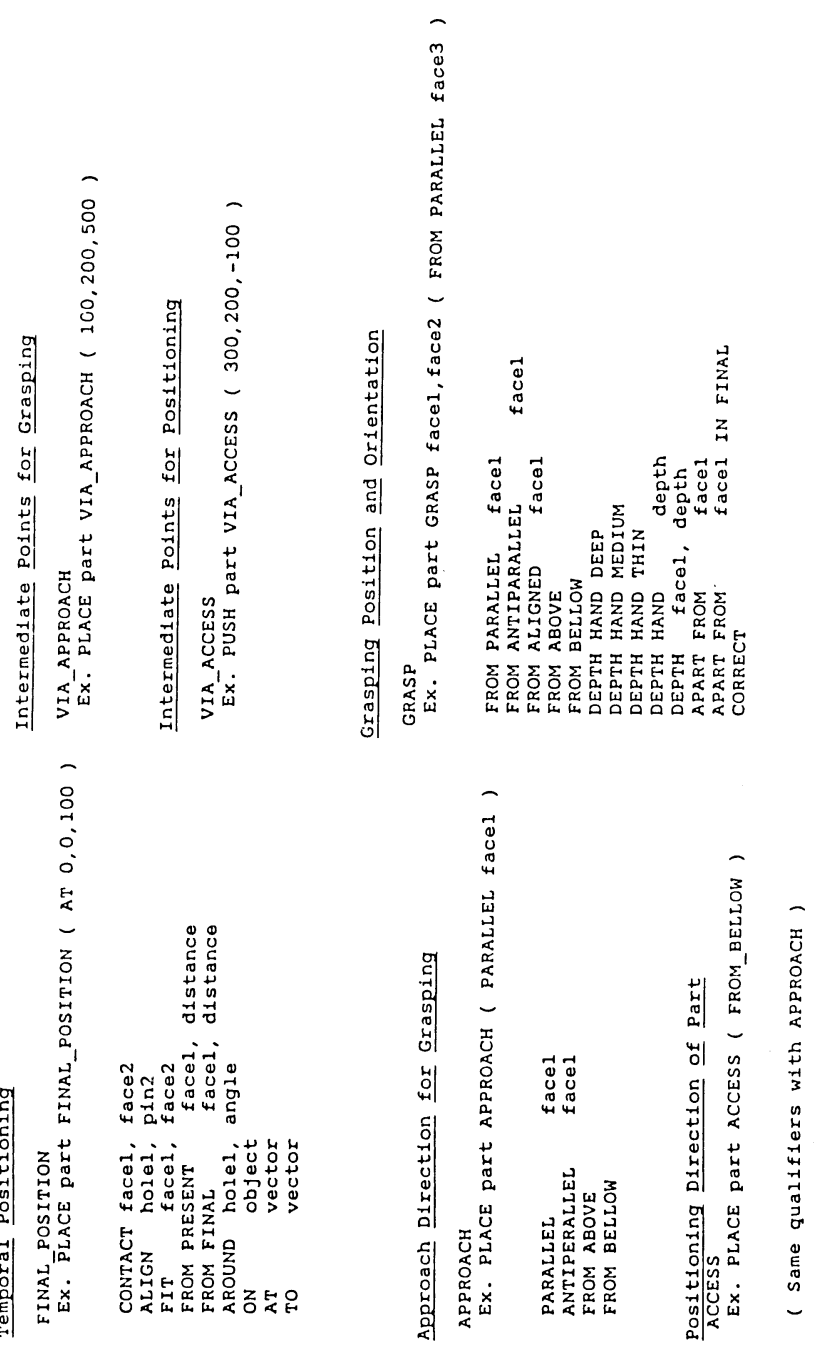

してPLACE (部品を持ち上げて移動)， SLIDE (部品をずらす), ROTATE（あ る軸のまわりに回転)，穴・軸のはめ合わ せ命命としてINSERT (部品の插入), SCREW (㸚じ締め), PUSH (圧入)，分 離命令として REMOVE（部品を抜き去 る), LOOSEN（ねじをゆるめる），の 8 種を定義した。各々の作業命令は, 対象 部品名と修飾子とを付けて用いる。修飾 子には，一時的な組付位置を指示する FINAL-POSITION，把握の接近方向を 指示吋る APPROACH, 部品の組付方向 を指示する ACCESS, 把握までの途中経 由点を指示するVIA-APPROACH，部 品の位置決めまでの途中経由点を指示す るVIA-ACCESS，把握位置と姿勢を指 示する GRASP がある。修飾子が指定さ れない場合には，システムが適当な値を 与兄る。把握に関する修飾は，一度記述 すればその情報は環境モデルに加えら れ，以後システムはその值を使用する。 センサ情報を用いる作業のために， ランタイムシステムの機能に応じて, GET-POSITION（視覚センサを用いて 部品の位置の補正を行ら）と，バリ取り 作業用の TRACE (力と位置の制御を用 いて稜線をなぞる）の 2 つ命令を用意 した。

制御命令としては, DO 文, GO-TO 文 等がある、

\section{3. 環境モデルを用いた} ロボット動作の生成

作業命令が与えられると，システムは 逐次, 各命令を解釈し, 環境モデルの初 期状態を更新していく．本システムは， 作業実行時にセンサからの情報に従って 環境情報を管理するためのランタイムモ デルと, ランタイムモデルの情報を参照 する形式の動作レベル言語である中間 コードとを出力し，ランタイムシステム に引き渡す677. 図 3 亿組立作業命令とそ の結果生成された中間コードの例を示 す。

以下に，環境モデルの処理による口 ボット動作の生成をその手順に従って説 


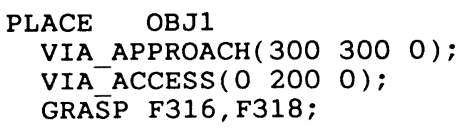

a) Assembly description

$\begin{array}{clc}1: & \text { speed: } & 0100 \\ 2: & \text { move: } & 5: \text { VIA1 } \\ 3: & \text { move: } & 6: \text { OBJ1_POS1 } \\ 4: & \text { speed: } & 0030: \\ 5: & \text { dmove: } & 7: \text { OBJ1_REL1 } \\ 6: & \text { close: } & 20.0 \\ 7: & \text { speed: } & 0050: \\ 8: & \text { move: } & 6: \text { OBJ1_POS1 } \\ 9: & \text { speed: } & 0070: \\ 10: & \text { move: } & 8: \text { VIA2 } \\ 11: & \text { move: } & 9: \text { OBJ2_POS1 } \\ 12: & \text { speed: } & 0030: \\ 13: & \text { dmove: } & 10: \text { OBJ2_REL1 } \\ 14: & \text { open: } & \\ 15: & \text { speed: } & 0050: \\ 16: & \text { move: } & 9: \text { OBJ2_POS1 } \\ 17: & \text { end: } & \end{array}$

b) Generated intermediate codes

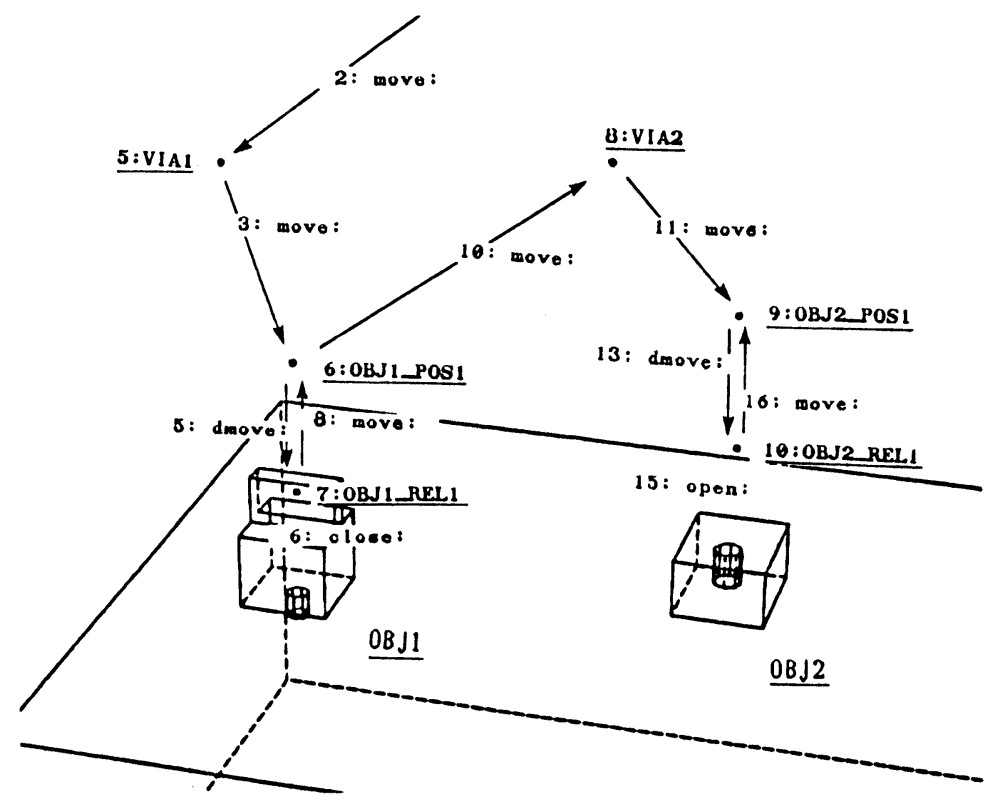

c) Generated motion : Run-time model includes underlined positional information

Fig. 3 Assembly description and its corresponding intermediate codes

明する。

（1）部品の移動先位置算出：修飾子 FINALPOSITION による指定がなければ部品の最終 状態の位置を移動先の位置とする. FINALPOSITION は, 面・面対偶 (CONTACT：重㸚合 わせ, FIT : 同一平面上に連続するような位置関
係), 軸・穴対偶 (ALIGN：中心軸が一致する位 置関係）等の付属語を組み合わせて移動先位置を 指定する.

（2）部品の安定性チェック：移動先での部品の 安定性をチェックする。まず, 接触面の傾きから 部品が滑り落ちないかを調べ, 次に部品の重心を 
重力方向に投影し接触面内に入ることを確かめ る.

（3）部品の把握位置算出：把握位置とは, ハンド の把握中心点に対応する，把握される部品側の点 である、言語で記述されない場合には，環境モデ ルの中のハンド固有のデータを用いて把握の深 さを決定し，その把握深さにおいて把握できる場 所の中央を把握位置とする。付属語 APART. FROM を記述すれば,特定の面に触れないように ハンドの位置を設定することもできる.

（4）マニピュレータの軌道生成：マニピュレー タの軌道は，(a)アプローチ点までの経由点（複 数指定可), (b) 部品へのアプローチ点, (c) 部品 の把握点，(d) アクセス点までの経由点(複数指定 可), (e) 組付位置へのアクセス点, (f) 組付位置 点，（g）アクセス点，を順次直線で結んで生成す る.ここで, アプローチ点-把握点間距離およびア クセス点一組付位置点間の距離は, ハンドに固有の データと，ユーザの与えるパラメータにより決定 する。

（5）ロボットの動作実現チェック：生成された マニピュレータの軌道上のいくつかのサンプル点 において動作の実現チェックを行う、サンプル点 は, 指定されたパラメータの值を越えない間隔で, 各直線軌道を等分割する点群である，各サンプル 点ではハンドの位置, 姿勢から各関節の変位を算 出する.この解を一般的に求めることは難しいの で，本システムでは異なる構造のロボットごとに 別の算出ルーチンを用意する手法をとっている.

算出された変位と, 環境モデルのリンクに関する 技術情報を照合し，動作の実現をチェックする。

（6）衝突チェック：口ボットの作業空間内での 物体を，（a）ロボット本体，（b）マニピュレータ， (c) 把握部品,（d）把握していない部品及び周辺 環境，に分類し，干渉の発生する可能性の大きい (a)-(d), (b)-(d), (c)-(d)の組合せについて, 衝突チェックを行う。まず各対象物の包絡体を用 いて粗い干渉チェックを行い，そこで干渉が検出 されたとき，実際の形状モデル間の干渉計算を行 5. 形状モデルによる干渉計算は実行時間で十数 $\min$ 以上かかる場合もあるのに対し，包絡体によ る粗い干渉チェックは数 ms で終わる. 包絡体は, 環境モデルの要素であるPARTを生成するとき にシステムが自動的に生成する。

（7）把握力チェック：把握対象物をハンドの中 で安定させて保持するのに必要な静力学的な力を

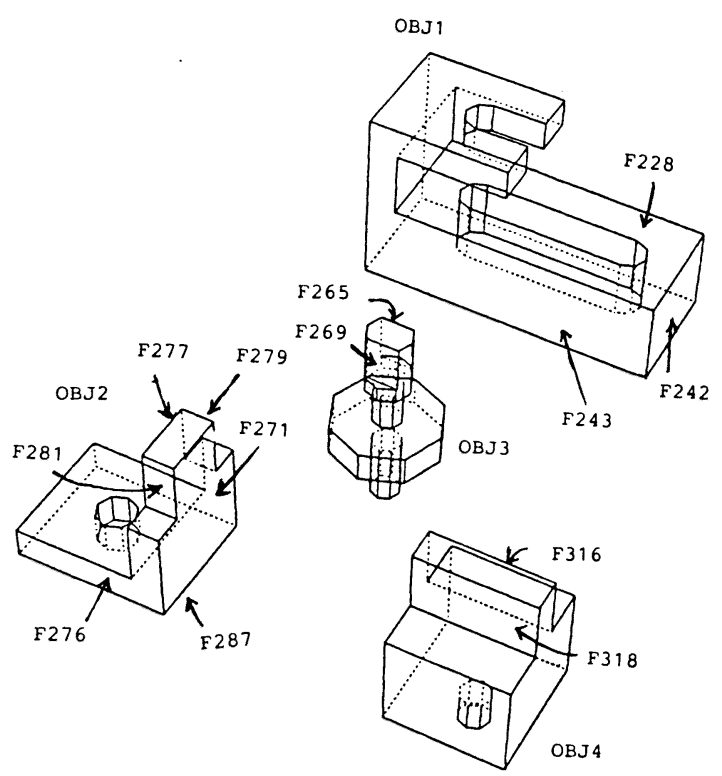

Fig. 4 Parts to be assembled

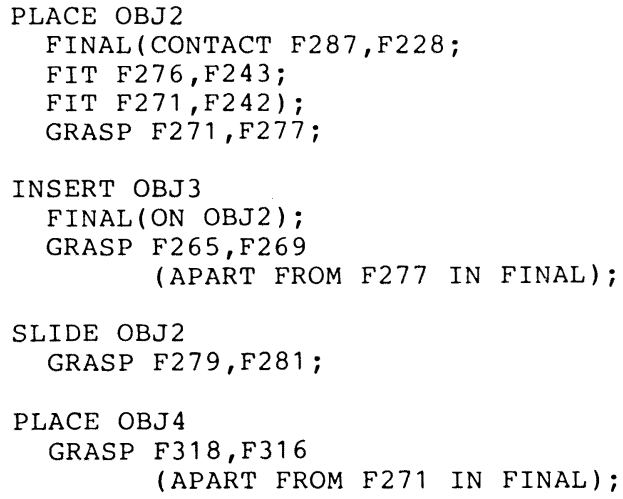

END

Fig. 5 Assembly program by assembly descrip. tion language

算出する。ハンドに必要な力は，こじ開けに対す る力とすべりに対する力に分類できる。こじ開け に対する力は, 力の釣合いより比較的簡単に算出 できる。すべりに対する力は，解析的に求めるの は困難なので，ハンドと部品との接触面を細かく 分割し，すべりの回転運動の中心を設定し，その 回転中心を収束計算によって求める。

\section{4. 実験}

本システムを $\operatorname{VAX} 11 / 780$ 上にインプリメントし 実験を行った。図 4 に実験に用いた組立部品群のモデ ルを示す。これらの部品の情報と, 初期状態と完成状 態の情報，および図 5 に示す組立作業プログラムから 

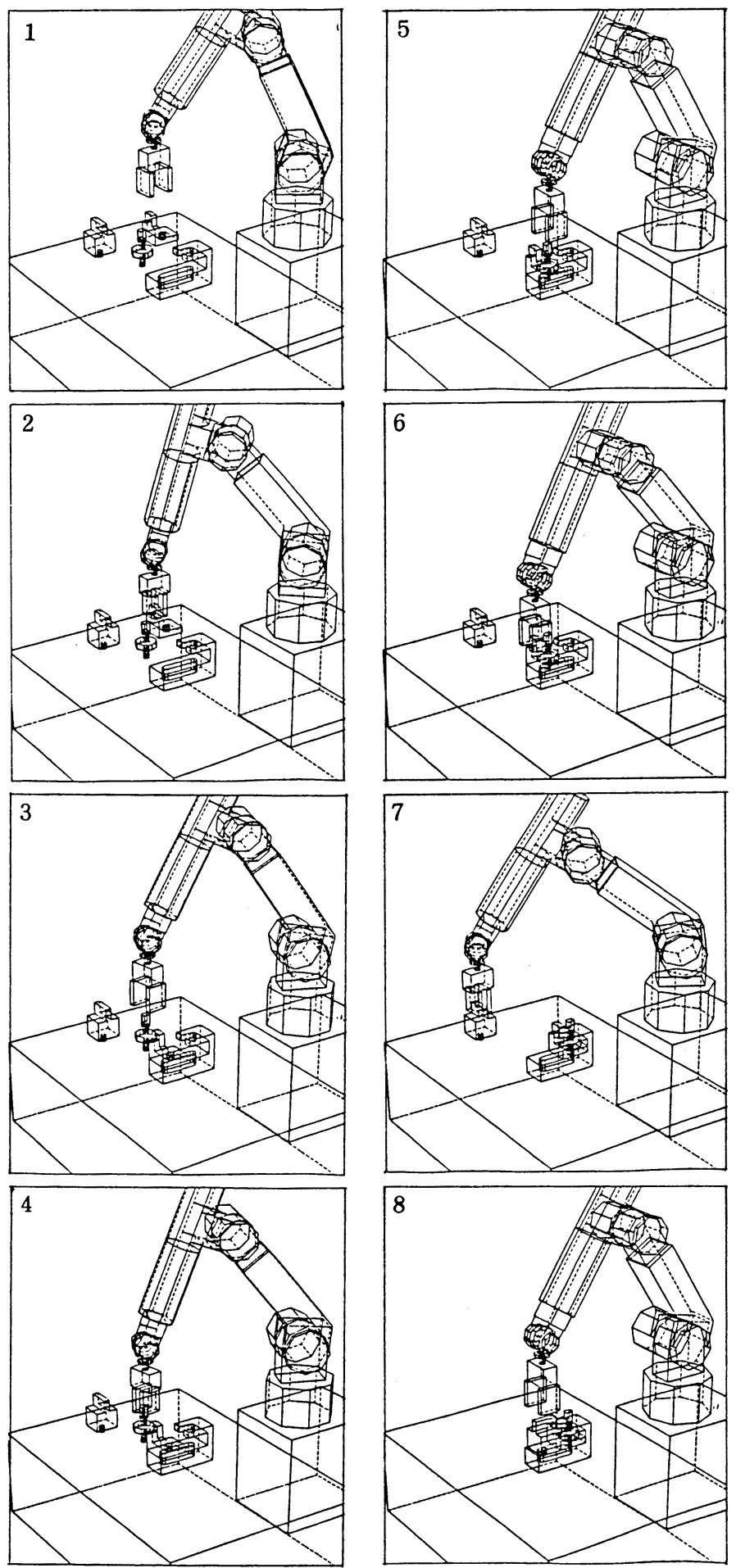

Fig. 6 Display of the simulated results
ロボットの動作を生成した。図 6 にその シミュレーション結果を示す。

\section{5. 結 論}

環境モデルを利用することで，高いレ ベルの組立作業記述からロボット動作を 生成するオフラインプログラミングシス テムを開発した。環境モデルの利用によ り，ロボット動作のプログラミングが簡 潔かつ容易に行えることが確かめられ た.今後の課題は, オフラインシステム でのセンサ情報の扱い, より高いレベル の作業記述言語の開発, 動力学などまで 考慮する動作実現チェック機能の拡充な どである。

\section{参 考 文 献}

1) T. Lozano-Perez : Robot Programming, Proc. IEEE, 71, 7, (1983) 821.

2) 小笠原 司, 井上博允：知能ロボット・プ ログラミングシステム COSMOS, 日本ロ ボット学会誌，2，6（1984） 507.

3）長谷川 勉：環境教示と環境モデル, 日本 ロボット学会誌, 2, 6 (1984) 599.

4) F. Kimura : GEOMAP-III : Designing Solids with Free-form Surfaces, IEEE CG \& A, 5, 3, (1984) 58.

5) F. Kimura, T. Sata and M. Hosaka : Integration of Design and Manufacturing Activities Based on Object Modelling, Advances in CAD/CAM, NorthHolland, Amsterdam, (1983) 375.

6) H. Hiraoka, K. Shimada, Y. Taguchi, K. Kondo, S. Yoshida, T. Yokoyama, F. Kimura and $T$. Sata: Utilization of Environment Models for a Sensory Equipped Industrial Robot, Proc. 15th ISIR, 1, (1984) 113.

7) 沜田憲司, 平岡弘之, 田口 靖, 木村文彦, 佐田登志夫：環境モデルとセンサ情報に もとづくロボットシステム（第 1 報, 第 2 報), 昭和 60 年度精機学会秋季大会学術講 演会講演論文集（1985）651，653.

8) T. Sata, F. Kimura and A. Amano: Robot Simulation System as a Task Programming Tool, Proc. 11th ISIR, (1981) 595. 